\title{
PENYULUHAN POSISI DUDUK YANG BENAR UNTUK KESEHATAN PUNGGUNG PADA SISWA/I SMPN 15 BANJARMASIN
}

\author{
Juliani Saputri $^{1^{*}}$, Sutikno ${ }^{2}$ \\ ${ }^{1,2}$ Program Studi Sarjana Fisioterapi Stikes Suaka Insan Banjarmasin \\ Email : julianisaputri07@yahoo.com
}

\begin{abstract}
ABSTRAK
Saat ini anak-anak semakin banyak menghabiskan waktunya dengan posisi duduk, baik di sekolah saat jam pelajaran maupun di rumah, di depan komputer atau televisi. Anak usia 4-15 tahun juga tidak banyak bergera selama rata-rata 7-8 jam sehari. Begitu juga dengan Siswa/I SMPN 15 Banjarmasin, dalam waktu 3 tahun selama mengikuti pembelajaran rata-rata menghabiskan waktu kurang lebih lima jam untuk duduk dikelas untuk satu hari. Dampak yang dapat ditimbulkan yaitu terjadinya asimetris lanjutan pada trunk dan scoliosis serta menyebabkan penurunan lumbal lordosis dan kiposis dari keseluruhan punggung anak. Selain itu, posisi duduk yang tidak ergonomis menyebabkan anak-anak bisa mengalami masalah nyeri punggung di usia muda. Perilaku ini perlu diperbaiki dengan memberikan pengetahuan tentang dampak yang diakibakan jika posisi duduk yang keliru dan cara duduk yang benar dengan metode ceramah dan tanya jawab. Hasil kegiatan ini didapatkan adanya peningkatan pengetahuan 91,25\% kelompok sasaran kegiatan. Melalui kegiatan ini diharapkan memberi dampak positif pada siswa/i untuk memiliki perilaku sehat terutama dalam menjaga kesehatan tulang dengan duduk posisi yang ergonomis.
\end{abstract}

Kata Kunci : Posisi Duduk, Kesehatan Punggung, Penyuluhan

\section{A. PENDAHULUAN}

Di masa sekarang ini anak-anak semakin banyak menghabiskan waktunya dengan posisi duduk, baik di sekolah saat jam pelajaran maupun di rumah, di depan komputer atau televisi. Kemampuan siswa untuk belajar secara efektif di sekolah erat hubungannya dengan pengaturan kelas dan hal tersebut tergantung pada banyak faktor salah satunya adalah posisi duduk (Will Paris et al, 2020). Menurut Justyna et al (2014) menunjukkan bahwa anak usia 4-15 tahun tidak banyak bergerak selama rata-rata $7-8$ jam sehari. Berbeda dengan berjalan dan berlari, otot tidak digunakan secara aktif saat duduk. Fungsi otot digantikan oleh efek penyangga kursi. Inaktivasi otot dalam jangka waktu yang lama menyebabkan melemahnya otot-otot yang tertentu. Posisi duduk yang tidak tepat dapat mengakibatkan masalah fisik dan ketidaknyamanan.

Grimmer et al (2006), menemukan bahwa remaja memiliki tingkat nyeri punggung yang tinggi yang dapat diverifikasi secara medis dan bertahan hingga dewasa. Degenerasi tulang belakang yang dipercepat akibat duduk dalam waktu yang lama menghasilkan tonjolan diskus lebih tinggi dibandingkan orang dewasa. 
Mempertahankan posisi duduk yang lama menghasilkan asimetris lanjutan pada trunk dan scoliosis serta menyebabkan penurunan lumbal lordosis dan kiposis dari keseluruhan punggung anak. (Justyna et al, 2014). Dalam beberapa tahun terakhir, prevalensi nyeri punggung bawah pada anak cenderung meningkat dari $2-11 \%$ hingga 27-51\% (Hwang et al, 2019).

Pengetahuan siswa mengenai posisi duduk yang benar saat ini masih kurang. Pendidikan merupakan salah satu cara yang dapat digunakan untuk meningkatkan pengetahuan seseorang. Pendidikan dapat diberikan pada berbagai bidang, termasuk kesehatan. Notoatmodjo (2012) menyebutkan bahwa pendidikan kesehatan adalah suatu proses yang dapat meningkatkan derajat kesehatan seseorang. Pendidikan kesehatan dapat diberikan kepada seluruh sasaran, namun harus menggunakan metode yang tepat agar informasi yang diberikan dapat diterima dengan baik.

Penyuluhan kesehatan pada siswa/I merupakan suatu hal yang amat penting dalam program promosi kesehatan untuk mengetahui akibat dari posisi duduk yang tidak tepat dan yang utama adalah mengetahui serta menerapkan posisi duduk yang benar untuk kesehatan punggung.

\section{B. METODE}

Solusi untuk menyelesaikan masalah ini adalah melalui pendidikan kesehatan dengan metode ceramah dan tanya jawab yang melibatkan siswa/i SMPN 15 Banjarmasin sejumlah 16 Orang. Pemberian angket sebelum dan sesudah penyuluhan dilakukan untuk mengetahui tingkat pengetahuan siswa terkait informasi yang diberikan. Pemberian penyuluhan/edukasi tentang posisi duduk yang benar untuk kesehatan punggung dengan melibatkan siswa/I SMPN 15 Banjarmasin bertujuan untuk memecahkan masalah terkait pengetahuan siswa mengenai posisi duduk yang benar untuk kesehatan punggung dan akibat dari posisi duduk yang salah.

Gambar 1. Kegiatan Penyulahan dengan Metode Ceramah dan Tanya Jawab

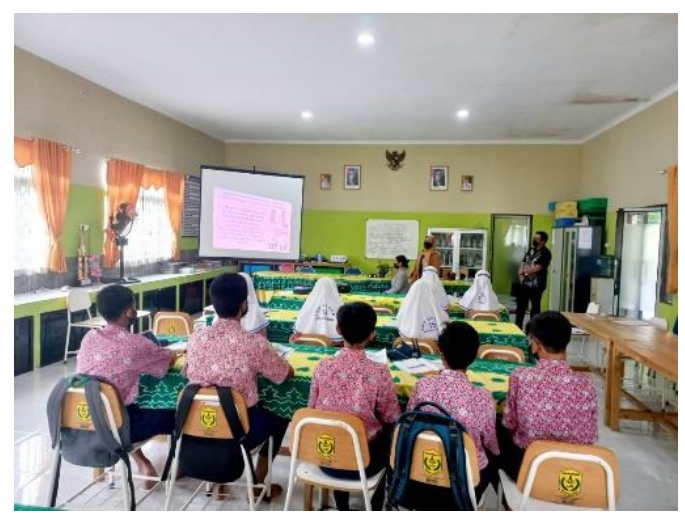


C. HASIL DAN PEMBAHASAN

Kegiatan pengabdian masyarakat kepada sisws/I SMPN 15 Banjarmasin tentang posisi duduk yang benar untuk kesehatan punggung telah berhasil dilakukan. Hal ini terlihat dari antusiasme peserta dalam mengajukan pertanyaan maupun menjawab pertanyaan dari pemateri serta terdapat peningkatan hasil nilai kuesioner/angket sebelum dan sesudah penyuluhan. Keberhasilan yang didapat dalam pengabdian masyarakat dapat dilihat pada Grafik 1. Dari grafik 1 dapat dilihat bahwa sebelum diberikan penyuluhan bagaimana duduk yang benar dan akibat yang ditimbulkan jika salah posisi duduk, tingkat pengetahuan para siswa sebesar $30 \%$ dan $70 \%$ belum mengetahui mengenai posisi duduk yang benar.

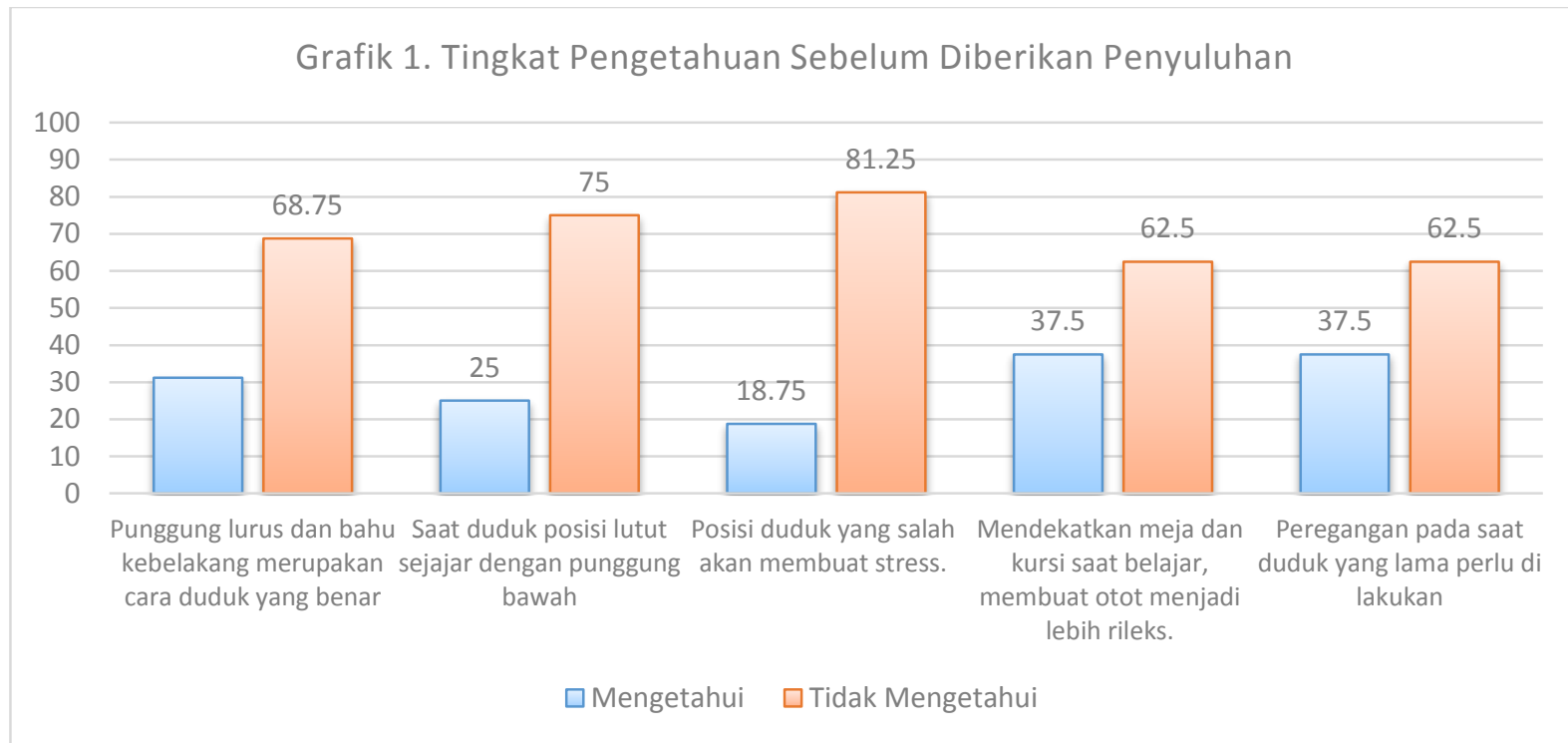

Rendahnya pengetahuan tentang cara duduk yang benar pada remaja sekolah tentu memiliki dampak salah satunya adalah gangguan pada sistem muskoloskeletal. Gangguan muskoloskeletal terjadi akibat otot menerima beban statis dan berulang secara terus menerus dengan jangka waktu yang lama, sehingga menyebabkan keluhan pada sendi, ligamen dan tendon (Noor, 2020).
Gangguan muskoloskeletal yang terjadi akibat cara duduk yang tidak ergonomis salah satunya adalah nyeri punggung. Dalam beberapa penelitian ditemukan posisi kerja duduk menjadi salah satu penyebab Low Back Pain (LBP) atau nyeri punggung bawah pada pekerja di Indonesia (Kusuma, Hasan, \& Hartanti, 2014). Tanda dan gejala Low Back Pain (LBP), cukup beragam antara lain terjadinya 
perubahan gaya berjalan dan fleksi, gangguan neurologi serta nyeri terutama saat beraktifitas (LeMone, Burke, \& Bauldoff, 2015). Nyeri saat beraktifitas akan menjadikan penderita cenderung melakukan imobilisasi, sehingga menjadi kurang produktif. Maka dari itu, pengetahuan tentang cara duduk yang benar akan membantu para remaja memiliki perilaku kesehatan yang lebih positif terutama dalam menekan kejadian masalah gangguan muskoloskeletal pada tulang punggung seperti Low Back Pain (LBP).

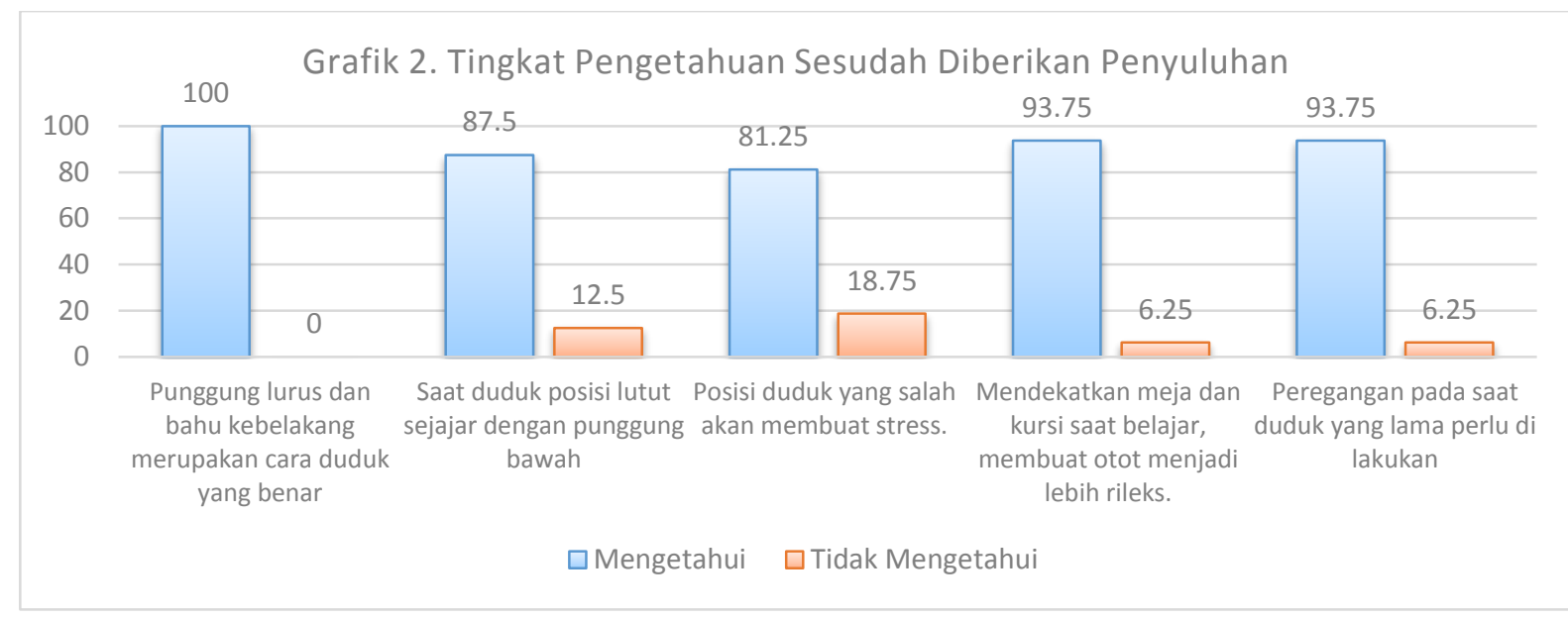

Dari Grafik 2 diatas memperlihatkan bahwa sesudah diberikan penyuluhan, tingkat pengetahuan para siswa sebesar $91,25 \%$ dan $8,75 \%$ belum mengetahui mengenai posisi duduk yang benar. Dengan adanya peningkatan pengetahuan ini diharapkan dapat mempengaruhi posisi duduk siswa saat belajar maupun melakukan aktivitas yang lain.

\section{KESIMPULAN}

Posisi duduk yang salah atau tidak sesuai ergonomis dapat mengakibatkan masalah fisik dan ketidaknyamanan terutama pada muskuloskeletal. Salah satu strategi untuk memfasilitasi siswa/I memperoleh informasi yang tepat tentang kesehatan musculoskeletal adalah melalui penyuluhan kesehatan. Melalui penyuluhan kesehatan tingkat pengetahuan siswa/i dapat meningkat signifikan. Melalui kegiatan penyuluhan diharapkan akan memberi dampak positif pada siswa/i untuk memiliki perilaku sehat terutama dalam menjaga kesehatan tulang dengan duduk posisi yang ergonomis. 


\section{DAFTAR PUSTAKA}

Drzal-Grabiec, Justyna., Slawomir, Snela., Justyna, Rykala., Justyna, Podgorska., \& Maciej, Rachwal. (2015). Effects of the sitting position on the body posture of children aged 11 to 13 years. Work. Vol.51, No.4, pp.855-865. DOI: 10.3233/WOR141901.

Grimmer K, Nyland L, Milanese S. (2006). Longitudinal investigation of low back pain in Australian adolescents: a five-year study. Physiotherapy Research International. Vol.11, No.3. DOI:10.1002/pri.340

Hwang, J., Louie, P.K., Phillips,F.M., An, H.S., Samartzis, D. (2019). Low back pain in children: a rising concern. European Spine Journal, vol.28, pp.211-213. doi: 10.1007/s00586018-5844-1.
Kusuma, I. F., Hasan, M., \& Hartanti, R. I. (2014, Maret). Pengaruh Posisi Kerja Terhadap Kejadian Low Back Pain Pada Pekerja di Kampung Sepatu, Kelurahan Miji, Kecamatan Prajurit Kulon, Kota Mojokerto. Jurnal IKESMA, 10(1), 59-66.

LeMone, P., Burke, K., \& Bauldoff, G. (2015). Buku Ajar Keperawatan Medikal Bedah Edisi 5, Volume 4. Jakarta: EGC.

Noor, P. (2020). Buku Ajar Gangguan Muskoloskeletal Edisi 2. Jakarta: Salemba Medika.

Notoatmodjo, S. (2010). Ilmu Perilaku Kesehatan. Rineka Cipta, Jakarta.

Will, Paris., Bischof, Walter.F., Kingstone, Alan. (2020). The impact of classroom seating location and computer use on student academic performance. PLOS ONE. 15(8), pp.121.

https://www.ncbi.nlm.nih.gov/pmc/ar ticles/PMC7406012/ 